\title{
Back to the Future: Aesthetics Today
}

\author{
Richard Shusterman
}

\begin{abstract}
A BSTRACT This paper originated as the keynote address at the conference "Aesthetics Today" organized by the Finnish Society of Aesthetics to mark its 4oth anniversary and was delivered at the University of Helsinki on March 1, 2012. Written for that particular occasion the sense of an oral presentation has been maintained. Shusterman's point of departure is the thesis that contemporary aesthetics can be characterized by a number of leading themes that mark a return to older aesthetic perspectives, after these perspectives have been neglected in modern philosophical discussions. The paper briefly outlines and explores three of these themes whose increasing importance in current aesthetics can appeal to historical antecedents, namely: a focus on perception, the expansion of the aesthetic field beyond the philosophy of fine art, and the close connection of the aesthetic and the practical. After that, Shusterman formulates a fourth theme in aesthetics today which incorporates the first three and whose value for contemporary aesthetics he seeks to highlight, namely: the somatic, as exemplified by somaesthetics. KEYWORDS Shusterman, Pragmatist aesthetics, somaesthetics
\end{abstract}

\section{I}

This conference was convened to mark the 4oth anniversary of the Finnish Society of Aesthetics, and I am very honored to celebrate it with you, especially since it coincides with the twentieth anniversary of my book Pragmatist Aesthetics, and the fifteenth anniversary of its Finnish translation (happily still in print). ${ }^{1}$ There is, of course, a familiar logic in marking an aesthetic event of forty years ago with the conference title "Aesthetics Today," but there is also a certain tension. If aesthetics has shown real progress, then it should not be what it used be, forty years ago, in 1972 when I was a student in Jerusalem working on analytic aesthetics, which was focusing at that time on the definition of art, the ontology of art works, and the logic of interpretation. Has aesthetics really progressed since then, and how? In some ways much of the discussion in analytic aesthetics seems fixated on the very same problems as in my student days, and it even seems to be recycling the same positions and debates with only minor variations.

Take for example the question of interpretation. Now, just as then, the debate is essentially waged over whether the true meaning or interpretation of the text is determined by the author, the implied author, or the reading public; now, just as then, we find the positions of objectivism and relativism debated, even if now these positions are qualified as being moderate or modest versions of intentionalism, relativism, or objectivism. ${ }^{2}$ My admired colleague Joseph Margolis - one of the original 
contributors to these debates in the 1970s and still a prolific polemicist in them - has often told me, I hope jokingly, that he likes this continuous recycling of the familiar questions in analytic aesthetics, because he can publish essentially the same arguments in papers today that he published in papers more than forty years ago. Good philosophy may indeed be perennial, but I think that a discipline may be in danger of stagnation when past theories or approaches are continuously recycled in very short intervals of time. That is one reason why my aesthetic research began to look beyond the analytic aesthetics paradigm (valuable as it is) to incorporate ideas from pragmatism, phenomenology, hermeneutics, poststructuralism, and East-Asian thought. I was striving for some kind of new philosophical synthesis, a new remix (in rap terminology) since all our philosophical ideas always already have some sort of mixed heritage.

I do not intend here to spoil this anniversary celebration by pessimistically complaining in the style of Ecclesiastes that "there is nothing new under the sun" and that our continuing research in aesthetics is merely an example of "Vanity of vanities, all is vanity." There may indeed be nothing in aesthetics today that is absolutely original without any historical precedent or influence, but there are significant and promising transformations underway that offer renewed enrichment and innovative insights. In fact, some of today's most promising trends for moving aesthetics forward into the future reflect a new revaluation of key perspectives from its more distant past, a past long before what it was forty years ago. My thesis, then, is that contemporary aesthetics can be characterized by a number of leading themes that mark a return to powerful older aesthetic perspectives, after a long period of modernity in which these perspectives were much diminished in philosophical discussion. I do not regard this as a decadent regression or arid recycling because the revived themes or perspectives are pursued with very different philosophical methods, concepts, and styles than they were in that distant past and they often issue in very different claims or conclusions.

In my paper I shall first outline three of these themes whose growing importance in aesthetics today can appeal to historical antecedents. In doing so, I do not mean to argue that their past prominence is a proof of their present value; instead I hope to improve our understanding of our aesthetic present by relating it to its past, while also illustrating how that rich past provides a wealth of resources that can be deployed in improving aesthetics for the future. After briefly exploring these three themes (each of them complex enough to warrant an entire lecture), I shall articulate a fourth theme in aesthetics today that although not very promi- 
nent in traditional philosophical aesthetics is strongly implied in the first three historically prominent themes and whose value for contemporary aesthetics I seek to highlight.

\section{II}

The first revived theme concerns the fundamental conception of aesthetics as essentially defined by a focus on perception, including our perceptual capacities, perceptual practices, and perceptual experience. Alexander Baumgarten, as we all know, founded the discipline of aesthetics by deriving its name from the Greek word for sensory perception "aisthesis" and by conceiving it as a general theory of sensory cognition. Aesthetics was meant to complement logic, the two together designed to provide a comprehensive theory of knowledge he termed Gnoseology. Though he regarded sensory perception as a lower faculty than conceptual thought, the project of aesthetics was designed to show how sensory perception (especially through its systematic cultivation) could nonetheless richly contribute to knowledge and improve not only our thinking but also our lives more generally, including (I cite his words) "the practical action of common life". Defining aesthetics as "the science of sensory cognition," Baumgarten further claims that the goal or "end of aesthetics is the perfection of sensory cognition as such." ${ }^{3}$

This perceptual definition of aesthetics was soon eclipsed by other conceptions of the field. Aesthetics was soon primarily conceived as theory of taste, as we see in Hume and Kant. Though taste is obviously a form of perception, the focus of these theories of taste were primarily on critical judgments of beauty or other forms of aesthetic value (like the sublime) that were seen as different from mere sensory taste sensations; and the primary aim was providing a standard or mode of objectivity for such judgments. ${ }^{4}$ With Hegel this approach is superseded and aesthetics is reconceived as essentially concerned with the philosophy of fine art rather than with matters of taste. Hegel opens his influential introductory lectures on aesthetics by pointing out that the term "aesthetics" is "so inappropriate" and "unsatisfactory" for the field he thinks it should designate, claiming instead that "the proper expression for [this] science is the "Philosophy of Art, or, more definitely, the 'Philosophy of Fine Art."' Hegel then goes on to argue that what matters in fine art (and thus in aesthetics as the philosophy of fine art) is not the sensory perception of art forms and the appreciation of the pleasures they afford but rather the ideas that fine art expresses. These ideas and concepts are ones that bring to clear consciousness not our particular perceptions but rather "the most com- 
prehensive truths of the mind." With Hegel aesthetics thus moves away from perception and toward conception; Aesthetics, he insists, is a "consideration of [art] by means of thought, not to the end of stimulating art production, but in order to ascertain scientifically what art is." ${ }^{5}$

Hegel's towering nineteenth-century figure cast its long influential shadow also onto twentieth-century aesthetics, even in the Anglo-American analytic tradition which has generally been so critical of his idealism and monism. Recall that this analytic tradition emerged in Britain from G. E. Moore and Bertrand Russell's rebellion against the prevailing neo-Hegelianism of the time. ${ }^{6}$ The Hegelian concept of aesthetics as the philosophy of fine art has nevertheless been the dominant conception of twentieth-century aesthetics, including analytic aesthetics. Major figures in this field (such as Arthur Danto and Joseph Margolis) often preferred to identify their work as philosophy of art rather than aesthetics. Fine art was certainly the dominant focus of the field, the key issues focusing on the definition of art, the ontology and individual identity of artworks, and the proper logic or methods for interpreting their meaning and establishing their value. ${ }^{7}$ The very notions of aesthetic experience and aesthetic attitude were strongly challenged (most notably by George Dickie); and even the strongest proponent of aesthetic experience, Monroe Beardsley, defined art as its prime instance or source, and defined aesthetics in artistic terms as "the philosophy of criticism" (the key term which appears in the subtitle of his major book, Aesthetics: Problems in the Philosophy of Criticism, 1958). ${ }^{8}$

In short, the idea of aesthetics as concerned more generally with sensory perception and experience was neglected. This was not only because of the narrower focus on fine art. Another crucial factor militating against aesthetics being concerned with perceptual experience was that such experience seemed too phenomenal, subjective, and elusive to satisfy the demands of an academic discipline aimed at generating real knowledge. Rather than experience or perception, analytic aesthetics felt it had to limit itself to the materiality of objects and events and to their material representations in language, symbols, texts, or scores because only such material objects seemed able to ensure objectivity. This approach in aesthetics was part of a more general trend in philosophy to make language, rather than experience or ideas, the fundamental substance for philosophical analysis, because language seems more public, shared, and objective, while the mental states of experience or consciousness seemed too private, elusive and ephemeral.

In the last two decades, however, contemporary aesthetics is reviving 
its original conception as focused on sensory perception. German philosophers, as I see it, have provided the original impetus, notably Wolfgang Welsch and Gernot Böhme, neither of whose work I encountered until I came to Berlin as a Fulbright Professor in the mid-nineties. Welsch's 1987 book entitled Aisthesis, which seeks a rehabilitation of sensory perception for aesthetics and for philosophy in general, goes even beyond Baumgarten and back to Aristotle to highlight perception's crucial role. (The book's subtitle is Grundzüge und Perspektiven der Aristotelischen Sinneslehre). His 1990 book Aesthetisches Denken made the same point, and elaborated aesthetic thinking as an especially effective way for understanding our contemporary reality. The case is restated in his Grenzgänge der Ästhetik (1996) and other texts. Gernot Böhme, a phenomenological thinker increasingly influential in aesthetics, likewise puts sensory perception at the core of aesthetics along with the notion of atmosphere understood as an elusive but powerful quality that hovers between the objective and subjective and that is grasped by aesthetic perception in books Aisthetik (2001) and Atmosphäre: Essays zur neuen Ästhetik (1995). ${ }^{9}$

Unfortunately, the impact of these scholars on the Anglo-American aesthetics has been very limited. But in that arena too, though from other sources, we have seen a refocusing of aesthetics toward sensory perception, as for example in Carolyn Korsmeyer's fine book of 1999 on taste. ${ }^{10}$ My own project of somaesthetics, first introduced in German in 1996 and then in English in 1997, expresses this trend of revaluing sensory perception for aesthetics. ${ }^{11}$ In elaborating the somaesthetic project I invoked Baumgarten for his focus on sensory perception but I also critiqued him by reconceiving the body as a perceptive soma in contrast to Baumgarten's disregard for the body in his account of sensory perception. ${ }^{12}$ Younger analytic scholars like Barbara Montero who explores "Proprioception as an Aesthetic Sense" also exemplify this increasing interest in aesthetics as sensory perception that is essentially and distinctively embodied, as do philosophers like Mark Johnson who brings cognitive science to bear on aesthetic perception. ${ }^{13}$ What helps make this refocusing on perception more palatable in the Anglo-American analytic arena is the larger philosophical trend toward the privileging of philosophy of mind over philosophy of language, compounded by philosophy of mind's renewed interest in questions of consciousness and qualities of perceptual experience that are not reducible to language. Moreover, prominent neuroscientists have taken an interest in explaining through neural correlates the workings and logics of aesthetic perception. Thus, aesthetic experience - long regarded with suspicion for its phenomenal, 
subjective character - is also getting more positive attention, after a period which I described in the mid-nineties that heralded "The End of Aesthetic Experience," to quote the title of a paper I published in The Journal of Aesthetics and Art Criticism in 1997.

2. Aesthetic experience (with its sensory appreciative perception of aesthetic qualities) constitutes a far wider realm than the experience of art. And this brings us to our second key trend of aesthetics today, the expansion of the aesthetic field beyond the Hegelian paradigm of the philosophy of fine art. There are several reasons for this change of perspective. There is the growing philosophical tedium (even when not explicitly expressed) of limiting aesthetics to fine art and the repeated rehashing of the issues of its definition, ontology, individuation of works, and the logic of their criticism. This discomfort is significantly heightened by two factors. First, so much influential contemporary fine art has been created expressly not for aesthetic appreciation but rather for political reasons or to make conceptual points, including the idea that art can be free of the aesthetic. Duchamp was an early pioneer here in explicitly designing his readymades to be aesthetically indifferent and claiming that "esthetic delectation" was inappropriate for such art. ${ }^{14}$

The second factor is that aesthetics in common usage clearly has much wider application than fine art and that our world seems increasingly aestheticized in so many different areas and fields outside the artworld - from politics to commerce, urbanism, technology, and even health. Although this aestheticization of the Lebenswelt is often described as a distinctive feature of postmodern culture, we should remember that aesthetic approaches to ethics and politics is also a far older, pre-modern phenomenon. ${ }^{15}$ Nevertheless, as postmodernism has heightened our awareness of the pervasive aesthetic dimension of everyday life, it has become increasingly unconvincing to limit aesthetics to fine art.

One obvious area into which aesthetics has expanded is environmental aesthetics, which partly signals a return to the concern with natural beauty, which was preeminent in pre-Hegelian aesthetics. Allan Carlson and Arnold Berleant are significant contributors to this trend in North America, as Gernot Böhme and Martin Seel are in Germany. Finland can certainly be proud of its own distinguished contributions to environmental aesthetics, which goes beyond merely nature aesthetics to consider diverse dimensions of our human environment, an environment that is both in and more than nature. Already in 1999 Finland published a book entitled Aesthetics in the Human Environment, edited by Pauline von Bonsdorff and Arto Haapala and published by Finland's 
unique International Institute of Applied Aesthetics at Lahti, a book to which I was glad to contribute an essay. ${ }^{16}$

Besides environmental aesthetics, I should mention at least two other notable areas where aesthetics has broken out of the confinement of fine art: the aesthetics of everyday life and the aesthetics of popular art. Finnish aesthetics has done very significant work in both of these areas, particularly in the former, I believe. There is perhaps no point then to belabor the fact that we find throughout the international field of aesthetics an increasing focus today on the aesthetics of the ordinary, and a wealth of article and book titles with phrases such as "aesthetics of everyday life," "everyday aesthetics," "aesthetics of the ordinary," "the aesthetic in ordinary experience." I have no time here to probe the complexity and insights of this rich field of research, but I should at least point out a basic ambiguity in the notion of everyday aesthetics, which contains two different conceptions or ways of aesthetically appreciating ordinary objects and events or commonplace, everyday practices.

The first notion puts its emphasis on the ordinariness of the everyday, while the latter instead highlights the particular aesthetic character in which ordinary, everyday things can be appreciated through aesthetic perception and thus transfigured into a special experience. This second conception of everyday aesthetics emphasizes aesthetics' root meaning of perception but also the important idea that aesthetic experience is a matter of conscious, concentrated attention that is essentially aware of itself as focused or heightened experience and whose object is the target of such explicit attentive consciousness and is appreciated as such. The first conception of everyday aesthetics is resolutely focused on appreciating the ordinary as ordinary, so the aesthetic quality or feeling appreciated in this first kind of everyday aesthetics would not call special attention to itself as an intense quality or powerful experience. It would instead be like appreciating dull weather with an ordinary, dull appreciation of its dullness, rather than a sudden spectacular vision or special experience of its dullness. In contrast, the second conception of everyday aesthetics is about the transfiguration of ordinary objects or humdrum commonplace events into a heightened perceptual experience that is characterized by explicit, intensified appreciative awareness.

Perhaps these different conceptions are simply poles on a continuum, and are not mutually exclusive. While recognizing the validity of the first conception, I confess to find the second more useful if aesthetics is conceived melioristically as a field of study aimed at enriching our lives by providing improved perception and more rewarding aesthetic experi- 
ence. From this perspective, aesthetic appreciation of ordinary objects and events serves to enhance and sharpen our perception of them so that we can derive from them the richest experience and most enlightened perception they can offer. If this second approach seems paradoxical because its heightened perception renders the ordinary somehow extraordinary in experience, there is also a paradox in the first conception; namely, if the everyday is experienced in the most ordinary, habitual, unconscious way, then how can one really speak of aesthetically appreciating it at all, if there is no explicit awareness of the experience.

The second conception attractively offers an alternative to the principal path that fine art felt compelled to pursue to achieve the similar goal of rendering our perception more conscious, focused, and thus rendering our experience both richer and more memorable. That path plies the method of defamiliarization by making difficult. According to the Russian formalist Viktor Shklovsky who formulated this method of "making strange," the technique purposely "makes perception long and laborious," because the perceptual process in art has a purpose all its own [is an aesthetic end in itself] and ought to be extended to the fullest." ${ }^{17}$ Underlying this argument is the assumption that art's aesthetic forms must be difficult in order to compel the prolonged attention needed to render our perception of things more fully conscious and clear. One proven danger of this technique, however, is that such difficulty alienates art from the everyday lives of people. Such difficulty undemocratically confines art to a privileged elite, while also isolating it even from that elite's praxis of everyday living. The awakened consciousness version of everyday aesthetics, I believe, offers the same sort of transfiguring intensity of awareness, perception, and feeling (and the enriched, more meaningful living this brings), but without high art's alienating difficulty and isolating elitism. Of course, this alternative path of enhanced, awakened perception of the ordinary, though it requires no special artistic erudition or access, has its own difficulty. For it requires some sort of discipline or askesis of perception, a special quality of attentive consciousness or mindfulness, one that opens a vast domain of extraordinary beauty in the ordinary objects and events of everyday experience that can be transfigured by such mindful attention. Whether this transfigurative vision gives us not only beauty but also deeper ontological truth is a matter for speculation that I will not pursue here. ${ }^{18}$

There is another sort of ambiguity in the idea of everyday aesthetics I should mention. Very often the term is applied to the aesthetics of activities that are part of everyday life in the sense that they belong to the real world rather than the artworld and are done by ordinary individuals 
on a regular basis. The aesthetics of food, drink, fashion, and sports can be classified as everyday in this sense because we do eat, drink, and dress everyday and many of us also exercise very regularly, if not daily. But there are aesthetic experiences of such everyday activities that are markedly different from the ordinary experience of them, and not simply because of a transfiguring quality of attention through special mindfulness but rather because of a special quality of the object or event being experienced that can be classified as ordinary in a general sense of belonging to the real world of normal life rather than the artworld but also be extraordinary in terms of its quality. Compare, for example, the discriminating tasting of an ordinary meal combo at Subway and an exquisite dinner with a superb wine; a humdrum frock and one's favorite cocktail dress; a regular workout and an inspired aerobics class by a great instructor, an enjoyable episode of nightly lovemaking versus one that stands out as extraordinary because of its creativity, intensity, or meaning.

Further analysis of the notion of everyday aesthetics is surely needed here, but I should move on to the aesthetics of popular art, which seems to command even more attention. When I first wrote about the aesthetics of popular art - focusing on rap and funk in the late 1980 and early nineties - there was very little discussion of such topics. The situation has enormously changed. Not only does popular art appear as a distinct topic in the major Routledge, Blackwell, and Oxford companions to aesthetics, but it also issues in numerous book-length studies and anthologies that either treat popular art as a whole (such as Noël Carroll's Mass Art) or instead focus on particular popular art genres (usually of music or film). Interest in popular art is so great that it has spawned, since the year 2000, a series of anthologies entirely devoted to popular culture and philosophy, whose articles often include aesthetic issues of popular art. (Two of the first 8 volumes of this popular series with Open Court that now runs to more than 60 volumes were co-edited by former students of mine at Temple, Mark Conard and Aeon Skoble). And since 2007 there is another series on philosophy and pop culture published by Wiley-Blackwell with more than 30 volumes.

If the growing body of aesthetic theory in these areas reflects a liberation from the exclusive cultural dominance of fine art, this does not entail a rejection of fine art's enduring value and importance. Instead, aesthetics can be more usefully pluralistic, devoting inquiry both to the most elevated fine arts and the most common everyday aesthetic practices and popular artistic forms. I argued for this pragmatic pluralism already in the first edition of Pragmatist Aesthetics in 1992, when I included a chap- 
ter on the high modernist art of T. S. Eliot's poetry and another on the then new popular art of rap music..$^{19}$ In reacting to misguided critiques that took the book's interest in the aesthetics of popular art as a rejection of fine art, I formulated this pluralism even more explicitly by invoking the logical principle of inclusive disjunction: namely, an inclusive either/ or in which the acceptance of one of the disjunctive options does not entail a rejection or exclusion of the others. ${ }^{20}$

3. The third theme from aesthetics' pre-modern past that has become prominent today is the close connection of the aesthetic and the practical, after two centuries of conceiving the aesthetic as essentially opposed to practicality and functionality. Kant's formulation of this aesthetic/ practical contrast and his famous definition of the aesthetic in terms of disinterestedness and purposefulness without purpose have been tremendously influential and in some ways very helpful for establishing art's autonomy and defending its independence from ethical and political dictates and from criteria of crass expediency or mercantile utility. Baumgarten's original philosophical project of aesthetics, however, was practical in at least two senses. First, the goal was not mere descriptive truth for truth's sake but involved the melioristic aim of improving sensory perception not only to give "science" and "the liberal arts" "appropriate materials" or "good foundations" to work with but also to make us better equipped to succeed "in the practical action of common life." In short, aesthetics was designed as a normative project meant to be applied beyond its own practice and even beyond the domain of fine art. Second, aesthetics did not merely consist of theorizing; it included practical exercises to cultivate improved sensory perception, which Baumgarten described as askesis or exercitatio aesthetica. ${ }^{21}$ Rather than mere contemplation, aesthetics meant action.

In ancient times, the application of aesthetic training and perception for practical ends lies at the heart of Confucian ethics and politics, which rest on the twin aesthetic principles of art and ritual. In The Analects, ${ }^{22}$ Confucius insists on the ethical importance of "achieving harmony" rather than mere obedience to fixed moral codes or commandments, and he likewise stresses the important ways that aesthetic practices such as music and ritual help establish and preserve such harmony (1.12). An exemplary person who serves as a model for ethical conduct thus must be aesthetically shaped by attuning his character through "the rhythms of ritual propriety and music" (16:5). The Confucian linking of virtue with aesthetic appearance is further strengthened by its emphasizing the "proper countenance", "demeanor, and "expression" that virtue should 
display and that contributes to successful harmony (8:4). Entire passages of The Analects are thus devoted to describing the kind of bodily bearing, facial expression, and even clothing that demonstrates such virtue.

Confucius emphasizes that virtue wields its power not by moral commandments, threats, and punishments but by attraction that works through aesthetic means. "The exemplary person attracts friends through refinement, and thereby promotes virtuous conduct (ren)" (12.24) because one wants "to stand shoulder to shoulder with" such persons by being likewise virtuous (4.16-4.17). In the same way, Xunzi insists on the aesthetical-ethical power of music and ritual for shaping the person's character and behavior into a more successfully harmonious form that contributes to the harmony of the wider social group. ${ }^{23}$ Xunzi clearly explains how ritual's aesthetic practice combines the "full realization" of "both emotion and form" to achieve "pleasure and beauty" and instill the rationality of order and the knowledge of "the mean" (19.2c; 19.2d). Ritual's aesthetic is eminently practical in not only nurturing and channeling emotional expression but in formally shaping such emotional expression to be more fitting, balanced, ethically and socially appropriate, and beautiful. It thus improves the inner character while also influencing the conduct of others toward greater harmony. Xunzi therefore claims ritual as "the root of strength in the state" (15.4). Similarly, he argues with respect to music that because it "purifies the inner mind", "music is the most perfect method of bringing order to men" and thus has crucial ethical, social, and political importance (20.1; 20.3).

Though Plato broadly condemned the mimetic arts of his time in Book $\mathrm{X}$ of The Republic, in earlier books of this dialogue and in his later work The Laws, he affirms the crucial role of beauty and art in creating the ethical character necessary for justice. Arguing that justice is essentially a mental virtue constituted by the ruling of the proper order in the human soul, Plato then projects that view of the right ruling order onto the public order of the state and insists that not only our intellects but our feelings and desires must be educated to discern and appreciate the right order, so that we will desire and love it. The harmonies of beauty are therefore advocated as crucially instrumental in such education (Republic 401-402). This idea has a long heritage in Western thought. Even after Kant (who recognized beauty as a symbol of morality), the idea of applying aesthetics to practical matters can still be found in Schiller's On the Aesthetic Education of Man, where aesthetic perceptions are expressly invoked as the necessary key to ethical and political transformation. But the dominant post-Kantian line was to preserve aesthetics' freedom from 
functionality, an idea reinforced by nineteenth century fin-de-siècle art for art's sake and twentieth-century modernism.

Today however, we see a renewed recognition of the practical import of aesthetics. Here in Finland, since the mid-nineties, this recognition has been institutionalized in the International Institute of Applied Aesthetics at Lahti (on whose international Board I have been proud to serve since its inception). But looking beyond this shining institutional exemplar, the practical is evident in several key areas of contemporary aesthetics. It is expressed in the analyses of the practical arts of living (such as cooking, fashion, cosmetics, home decoration, and environmental design) that we already noted in everyday aesthetics. Besides these more specific aesthetic practices, there is the general art of living and stylization of self that Foucault helped make famous through his notion of aesthetics of existence and that Richard Rorty, Alexander Nehamas, and I have developed in different visions of the aesthetic life.

These manifestations of the aesthetic-practical connection are essentially concerned with the ethical question of how to live in real life, but we should also realize that in contemporary aesthetics of fictional works of art there is increased discussion of the relevance of ethical matters to the work's evaluation. Moreover, contemporary aesthetics' potent mix of aesthetics and politics can be seen in the emancipatory agenda of feminist aesthetics and black aesthetics, as well as some forms of pragmatist aesthetics. This political turn in philosophical aesthetics was largely inspired by the strong political turn in contemporary art in the eighties and nineties. Walter Benjamin is famous for noting how the mix of aesthetics and politics served fascism, but we should recall that he equally noted its use in communism's efforts of revolutionary emancipation. ${ }^{24}$ In any case, whatever its political uses, aesthetics today can no longer deny its practical functionality.

\section{III}

I turn now to a fourth theme of contemporary aesthetics, one that incorporates (and I use this term pointedly) all three themes already discussed. This fourth theme is the somatic, as exemplified by the project of somaesthetics but also by other somatic approaches to aesthetics that are less global or more limited (for example, body-oriented feminist aesthetics; the aesthetics of sport as advocated by Hans Ulrich Gombrecht; ${ }^{25}$ or the embodied cognition approach of Mark Johnson which has a more general scope but lacks a practical, meliorative component). How does this somatic turn, taking somaesthetics as our example, embody the first three themes?

First, the perceptual turn in aesthetics implies the somatic because 
our sensory perception depends essentially on our bodily senses, not only the more familiar teleceptors or five traditional senses, but also more distinctively bodily senses such as those of proprioception and kinesthesia. Second, the somatic turn likewise reflects the extension of aesthetics beyond the realm of fine art. Consider the definition of somaesthetics as the critical, meliorative study of the body as a locus of sensory aesthetic appreciation and of creative self-fashioning. If the first part of this definition focuses on the somatic medium of sensory perceptions that we appreciate aesthetically and that are not limited to perceptions of works of art, the second part insists that our bodies are also media through which we can express ourselves aesthetically and create aesthetic experience that is replete with meaning not only for others but also for ourselves. Various activities associated with everyday aesthetics outside the artworld are covered in the scope of somaesthetics: practices of cosmetics, grooming, fashion, and, of course, various body disciplines that reshape our somas not only in terms of external form (such as dieting) but also with respect to our enduring but modifiable bodily schemata or dispositions that structure or guide our perceptions, feelings, and actions. Somaesthetic disciplines such as yoga or aerobics offer everyday practices that provide the inner aesthetic satisfactions of harmoniously structured and often intense body experiences but also provide ways of reshaping one's external postural and gestural form in more aesthetically rewarding ways.

In going beyond the borders of fine art, contemporary aesthetics has had to become more interdisciplinary. I have not listed interdisciplinarity as a separate theme in this paper, because it seems more abstractly methodological than the others, but it would not be unreasonable to name it as a trend in aesthetics today. For instance, in doing environmental aesthetics (whether with respect to natural or densely constructed environments) include some geographical or ecological research or theories of urbanism. Likewise, in theorizing the aesthetics of personal appearance or the aesthetics of home decorations, one is led into sociology and cultural studies that illuminate the social meanings of our choices in taste. Why, for example, do people of certain cultural groups want to straighten their hair and lighten their skin, while those of other groups want to tan and get their hair permed? Tastes in what looks appetizing in food presentation, home decoration, or car design similarly will differ with different social classes, as Pierre Bourdieu's studies have made evident.

Moreover, to understand fully some of those food, home, or automotive choices it may be important to investigate factors of nutrition, social class, 
political economy (including national or local economic interests), and environmental sustainability. To take one more example, appreciating the full aesthetic power and meaning of a given religious ritual may demand a thorough study of how that ritual is embedded in a specific ideology of religious belief and a particular network of community traditions. I am not merely making the simple point that the study of aesthetics goes beyond the mere look of things; I am also suggesting that the immediate perception or look of things is always already shaped by a cultural and cognitive background whose understanding is necessary for a full appreciation of what that look is and means. Although I have argued that by going beyond the limits of fine art, the scope of aesthetic inquiry is also encouraged to be more interdisciplinary, I should insist that interdisciplinarity can also be wonderfully applied to the study of fine art, as Michael Baxandall and Serge Guilbaut have done in different ways with respect to Renaissance Italy and twentieth-century New York and Paris. ${ }^{26}$

Interdisciplinarity is key to the conception of somaesthetics, though its roots are grounded in the discipline of philosophy, particularly pragmatist aesthetics and the idea of philosophy as a way of life. Somaesthetics must be interdisciplinary because understanding and cultivating the body's use as a medium of sensory perception and creative self-expression can only be properly pursued by studying the body's diverse roles and functions in different areas of life and also in the differing environments (both natural and social) that enable, constrain, and otherwise structure its experience and performance. Such study involves natural sciences such as anatomy and physiology but also, of course, the social sciences and the humanities and arts.

I return from the meta-theme of interdisciplinarity to the third major theme discussed earlier - the practical turn. It too is also expressed in the project of somaesthetics in several significant ways. First and most generally, the very concepts of practice and the practical necessarily imply action; and all human action requires the body. Besides this very abstract point, somaesthetics has practical import because actions can be performed more effectively and gracefully through improved somaesthetic ability. Moreover, somaesthetics was explicitly conceived as a field of practice as well as theory. For this reason, besides the branches of analytic somaesthetics (concerned with descriptive facts and theory) and of pragmatic somaesthetics (concerned with methods of somatic improvement), there is also the branch of practical somaesthetics that involves actual bodily practice rather than mere discourse about practice. For this same reason, I give practical workshops in somaesthetics and not just lectures 
about it. One of these workshops was given here in Finland, in June 2009, at the Sibelius Academy's center in Kuninkala near the maestro's home in Järvenpää. Clips from a practical workshop I did with dancers in France are available at https://sites.google.com/site/somaesthetics/home/videoclips. This practical work is crucial to somaesthetics as a meliorative discipline aimed at improving not only our understanding of body consciousness but also the acuity and performance of such consciousness and of the somatic behavior it guides. By my pragmatist lights, such improvement cannot be done simply through textual means alone. It requires practical somatic efforts beyond reading, writing, speaking, and listening, though all those discursive actions (which are also somatic) are also important for guiding the non-discursive practical body work.

A further way that somaesthetics reflects the practical trend in aesthetics today is that the leading emancipatory political projects in aesthetics that highlight the practical stakes of aesthetic activism and aesthetic cultural legitimation are focused on race and gender, whose very concepts are based on the body and its appearance. There can be no gender identity or racial identity without a generic body image to signal that identity - even if that body image is an inaccurate stereotype. Ethnicity is also largely profiled through bodily style, whether this is in visual appearance (facial features and fashion) or bodily behavior (including gesture but also habits of eating, walking, etc.). ${ }^{27}$ The somaesthetics of race, gender, and ethnicity goes beyond external bodily form to recognize that also the subject's own body consciousness (including her aesthetic tastes) are shaped by her sense of racial, gender, or ethnic identity, a sense that is often implicit. Heightened body consciousness can help the subject become more aware of these implicit dimensions of her identity and taste; and such awareness is needed to transform implicit feelings, tastes, and behavior patterns, if the subject indeed wants to change herself or reform her habits in some way.

Moreover, one's own body consciousness can be developed to be more perceptive of our own implicit visceral reactions to ethnic others that can strongly influence our behavioral interaction without our knowing it. Many of our unfortunate, unintentional displays of racial or ethnic prejudice take this form, as I've argued in my book Body Consciousness. ${ }^{28} \mathrm{Be}-$ sides such problems of social interaction, somaesthetics can address a wide variety of practical problems in our daily living, ranging from overeating and poor digestion to back pain, accidents, slips of memory, and mistakes in typing. I address these issues in a paper called "Muscle Memory and the Somaesthetic Pathologies of Everyday Life," which is revised in my Thinking through the Body (Cambridge University Press, 2012). 


\section{IV}

I want to conclude my remarks by returning to the fine arts with which aesthetics has long been closely and beneficially connected. If aesthetics today has wisely rejected the Hegelian confinement to fine art, this does not mean that it should forsake that noble domain. In fact, a promising trend (less prominent than the others I've discussed but still discernible) is the more active role that philosophical aesthetics is taking in the criticism, exposition, and production of contemporary art. Arthur Danto, certainly one of the great twentieth-century names in aesthetics, eventually combined his art theorizing with a career in the practice of art criticism. My Chinese colleague Peng Feng, evolved from his appointment as professor of aesthetics at Peking University's Philosophy Department to become one of China's most important new art curators. His magnificently successful pavilion at the 2011 Venice Biennale (which, by the way, was based on somaesthetics $)^{29}$ led to the creation of an art criticism and theory department at Peking University, with him installed as its head. In the field of music, we have the example of Roger Scruton whose works in the philosophy of music are complemented by works of musical composition, including an opera. Arnold Berleant, well-known here in Finland, also combines his aesthetic theorizing with musical activities of composition and performance.

As for myself, after being frequently questioned by countless artists about the relationship between somaesthetics and contemporary art, I decided that I needed to make the connection clearer by inserting myself into the field of art practice. The result has been a continuing collaboration with the Parisian artist Yann Toma in a series of photographic and cinematic works realized in various venues in France, Florida, and Cartagena, Colombia. This collaboration grew out of Yann's interest in my writings in pragmatist aesthetics and somaesthetics, just as it also was spurred by my desire to realize one of the key ideas I have tried to advance since my conversion to pragmatist aesthetics in the late 1980 . The idea is that a philosopher of art should not be compelled to be simply a passive observer or distanced, disinterested judge but rather should be welcome to display close engagement and caring activism in his or her approach to the arts. To do so may involve taking on the job of theoretical advocacy (such as I did with the aesthetic legitimation of rap music) or of practical criticism of contemporary art where in taking a stand one can contribute to the artworld's reception of new art and thus perhaps also influence future artistic production. Such pragmatic activism may also involve curating shows or advising 


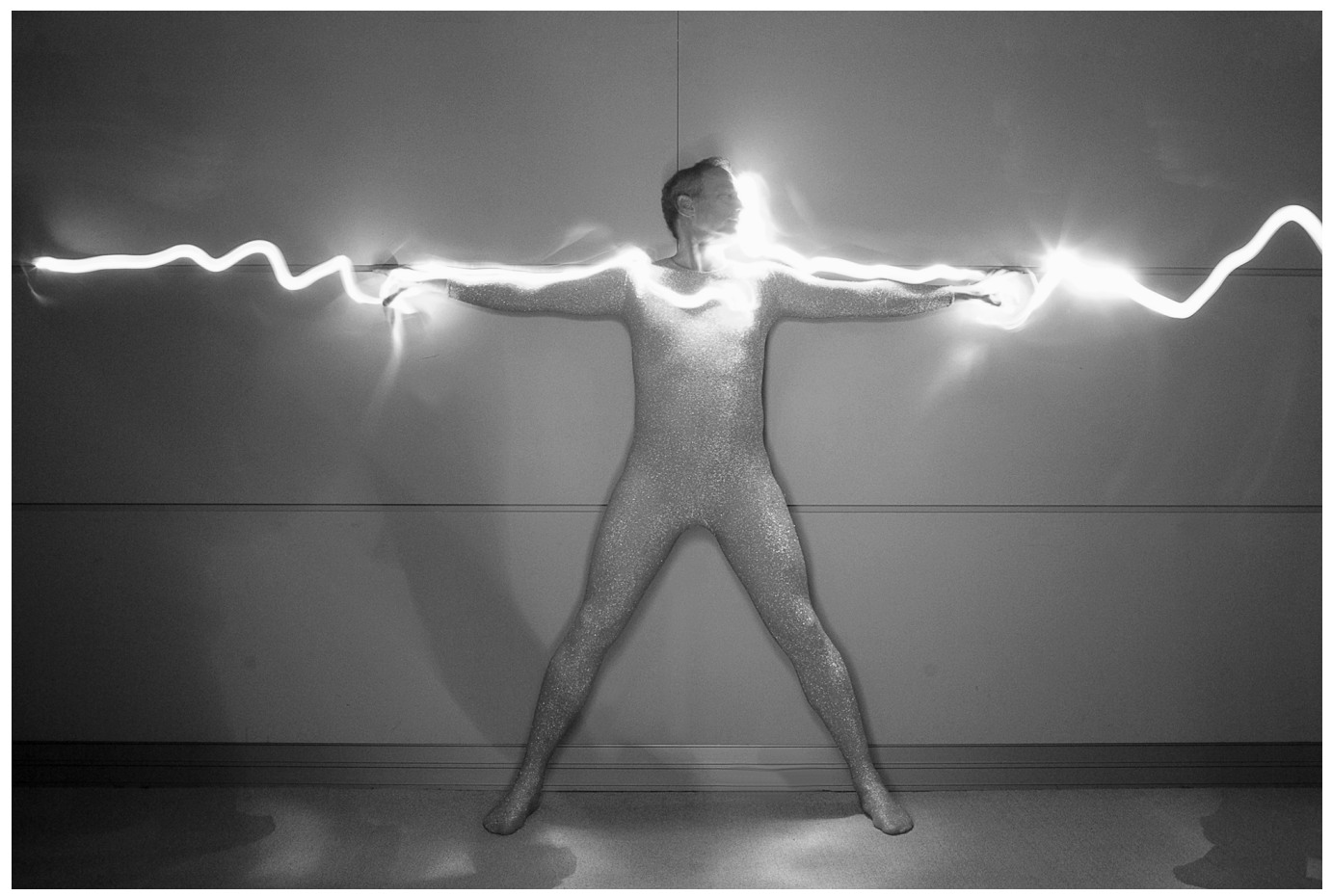

1. Yann Toma with Richard Shusterman:

Darsonvalisation, Royaumont 2010 
Back to the Future: Aesthetics Today

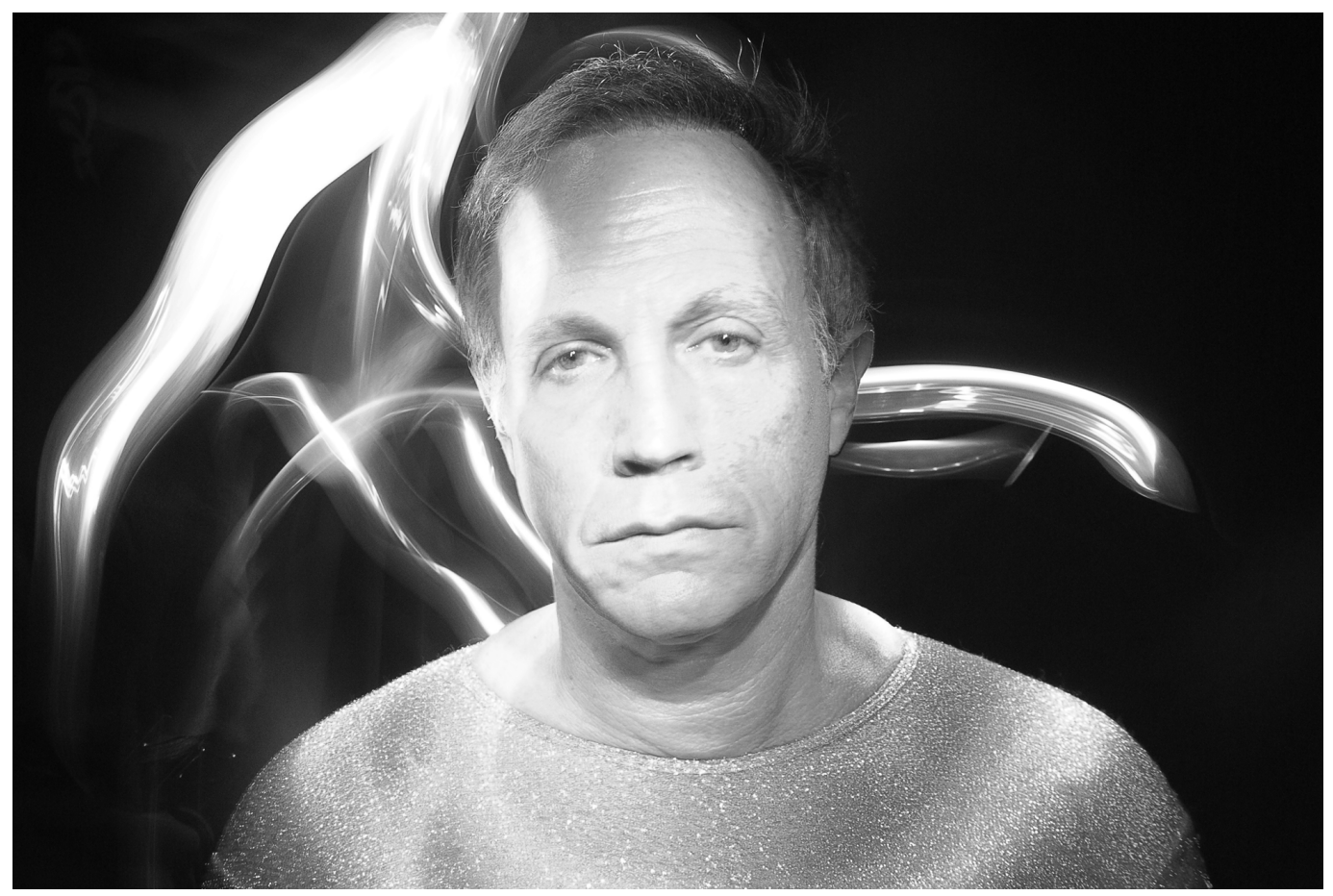

2. Yann Toma with Richard Shusterman:

Somaflux Headshot, Royaumont 2010 
artists and artworld institutions or collaborating with artists in producing works of art - or even producing art oneself, inspired by one's aesthetic theorizing.

One form of such aesthetic activism that converges powerfully with somaesthetics is the aesthetic philosopher's putting his or her own body not only into the cause of artistic reception and production but even into the artwork itself. This is the path I have taken in my photography and film collaborations with Yann Toma, where I appear in the somatic avatar of The Man in Gold, clothed in a shimmering gold Lycra body stocking. I have discussed this work, whose photographic dimension recalls Man Ray's space writing, in some recent texts, one published in last year's Montreal photography biennale catalogue and another in the recent special issue on photography in The Journal of Aesthetics and Art Criticism (February 2012). ${ }^{30}$ But here, to conclude, let me briefly share with you some images of this work, and thank you for your attention and understanding.

\section{Notes}

1. I would like to thank Arto Haapala and others of the Finnish Society for Aesthetics for honoring me with their invitation and providing me with some fine philosophical discussion.

2. The famous Beardsley-Hirsch debate about intentionalism that I know from my student years in the 1970s was emphatically recycled in the early 1990 s as reflected in an anthology in which two of my articles on interpretation appear. See Gary Iseminger, Intention and Interpretation (Philadelphia: Temple University Press, 1995). The same basic positions (and arguments) are still being frequently recycled in analytic journal articles today.

3. Alexander Baumgarten, Theoretische Ästhetik: Die grundlengenden Abschnitte aus der "Aesthetica" (1750/58), trans. from the Latin by H. R. Schweizer (Hamburg: Felix Meiner, 1988), para. 1,3, 14 .

4. For a comparative account of their theories from this perspective, see Richard Shusterman, "Of the Scandal of Taste: Social Privilege as Nature in the Aesthetic Theories of Hume and Kant," reprinted in my Surface and Depth: Dialectics of Criticism and Culture (Ithaca: Cornell University Press, 2002), ch. 5.

5. G. W. F. Hegel, Introductory Lectures in Aesthetics, trans. Bernard Bosanquet (London: Penguin, 1993), 4, 9, 13.

6. See J. O. Urmson, Philosophical Analysis (Oxford: Oxford University Press, 1956).

7. These four topics of identity, ontological status, interpretation, and evalu- 
ation formed the core of my analytic dissertation and first book, entitled The Object of Literary Criticism (Amsterdam: Rodopi, 1984). A revised edition of this book, whose introduction explains the continuities between this early analytic work and my later pragmatism, is published in French as L'Objet de la critique littéraire (Paris: Questions Théoriques, 2009).

8. For a detailed discussion of the analytic (but also the continental) critique of aesthetic experience, see my paper "The End of Aesthetic Experience," reprinted in my Performing Live: Aesthetic Alternatives for the Ends of Art (Ithaca: Cornell University Press, 2000), ch. 1.

9. Besides his study of these notions, Böhme has important things to say about the body as sensitive, perceptive Leib, and he has been a helpful critic of my work in somaesthetics. See Gernot Böhme, "Somästhetik - sanft oder mit Gewalt?" Deutsche Zeitschrift für Philosophie 50 (2002): 797-800

10. Carolyn Korsmeyer, Making Sense of Taste: Food and Philosophy (Ithaca: Cornell University Press, 1999).

11. Richard Shusterman, Vor der Interpretation: Sprache und Erfahrung in Hermeneutik, Dekonstruktion und Pragmatismus (Vienna: Passagen, 1996); and Practicing Philosophy: Pragmatism and the Philosophical Life (New York: Routledge, 1997).

12. Richard Shusterman, "Somaesthetics: A Disciplinary Proposal," Journal of Aesthetics and Art Criticism 57 (1999): 299-313.

13. Barbara Montero, "Proprioception as an Aesthetic Sense," in JAAC 64 (2006): 230-42, and Mark Johnson, The Meaning of the Body: Aesthetics of Human Understanding (Chicago: University of Chicago Press, 2007).

14. Marcel Duchamp, "A propos of 'Readymades," reprinted in Salt Seller: The Writings of Marcel Duchamp (Marchand du Sel), eds. Marcel Sanouillet and Elmer Peterson (New York: Oxford University Press, 1973), 141.

15. I elaborate this point in "The Convergence of Ethics and Aesthetics: A Genealogical, Pragmatist Perspective," in The Hand and the Soul: Ethics and Aesthetics in Architecture and Art, ed. Sanda Iliescu (Charlottesville: University of Virginia Press, 2009), 33-43.

16. Richard Shusterman, "Human Nature at the Schlachtensee," in Aesthetics in the Human Environment, eds. Pauline von Bonsdorff and Arto Haapala (Lahti, Finland: International Institute of Applied Aesthetics, 1999), 35-47.

17. Viktor Shklovsky, "Art as Device," in Theory of Prose, trans. Benjamin Sher (Normal, IL: Dalkey Archive Press, 1991), 5-6.

18. For further discussion of the transfigurative notion of ordinary aesthetics, see Richard Shusterman, Thinking through the Body: Essays in Somaesthetics (Cambridge: Cambridge University Press, 2012), ch. 13.

19. Richard Shusterman, Pragmatist Aesthetics: Living Beauty, Rethinking Art (Oxford: Blackwell, 1992). 
20. Richard Shusterman, Pragmatist Aesthetics: Living Beauty, Rethinking Art, 2nd ed. (New York: Rowman and Littlefield, 2000), x-xi.

21. For these points, see Baumgarten's Aesthetica, para. 3, 47-61.

22. I cite from The Analects of Confucius, trans,. Roger T. Ames and Henry Rosemont, Jr. (New York: Ballantine, 1998), referring here parenthetically to book and section numbers rather than to page numbers.

23. My quotes from Xunzi are from John Knoblock (trans.), Xunzi, 3 vols. (Stanford: Stanford University Press, 1988-1994). References are to book number and section number in Knoblock's translation.

24. Walter Benjamin, "The Work of Art in the Age of Mechanical Reproduction," in Illuminations (New York: Schocken, 1969).

25. Hans Ulrich Gumbrecht, In Praise of Athletic Beauty (Cambridge, MA: Harvard University Press, 2006).

26. Serge Guilbaut, How New York Stole the Idea of Modern Art (Chicago: University of Chicago Press, 1985); and Michael Baxandall, Painting and Experience in Fifteenth-Century Italy (Oxford: Oxford University Press, 1988).

27. For a detailed discussion of the multiple elements of bodily style, see Richard Shusterman, "Somatic Style," Journal of Aesthetics and Art Criticism 69, no. 2 (2011): 147-59, revised and reprinted in Thinking through the Body.

28. Richard Shusterman, Body Consciousness: A Philosophy of Mindfulness and Somaesthetics (Cambridge: Cambridge University Press, 2008), ch. 4.

29. For a discussion of the relationship between somaesthetics and the Chinese Pavilion of the 2011 Venice Biennale (curated by Peng Feng), see our interview in "Dialog on the China Pavilion of the 54th Venice Biennale", Art Press Paris, June 2011. Supplement Venice 2011, pp. 24-25, in English and French.

30. "A Philosopher in Darkness and Light," and in French translation, "Un Philosophe en ombre et en lumière," in Lucidité: Vues de l'intérieur/Lucidity: Inward Views, ed. Anne-Marie Ninacs (Montreal: Le Mois de la Photo à Montréal, 2011); and "Photography as Performative Process," Journal of Aesthetics and Art Criticism 70 (2012), 67-78. For a somaesthetic analysis and critique of my collaboration with Yann Toma, see Peng Feng, "Somaesthetics and Its Consequences in Contemporary Art," in The Next Thing: Art in the 21st Century, ed. Pablo Baler (Lanham, MD: Fairleigh Dickinson University Press, 2013). Further collaborative works with Yann (in photography, performance, and video) were exhibited at an art show I curated in Paris at the Michel Journiac Gallery (May-June, 2012). The show, entitled Aesthetic Transactions: Pragmatist Philosophy through Art and Life, included works of ORLAN, Carsten Höller, Tatiana Trouvé, Pan Gongkai, Thecla Schiphorst, and Luca Del Baldo (all artists with whom I had previously collaborated in some way). Images of the show as well as my catalog essay are available at: ttp://aesthetictransactions.webs.com/ 